\title{
Effect of Five Single Nucleotide Polymorphisms of ABCG5 and ABCG8 Genes on Ezetimibe Lipid-Lowering Response
}

\author{
Efecto de Cinco Polimorfismos de los Genes ABCG5 y ABCG8 \\ sobre la Respuesta Hipolipemiante a Ezetimiba \\ *,** José M. Caamaño; "Nicolás Saavedra; "Tomás Zambrano; **Fernando Lanas \& "Luis A. Salazar
}

CAAMAÑO, J. M.; SAAVEDRA, N.; ZAMBRANO, T.; LANAS, F. \& SALAZAR, L.A. Effect of five single nucleotide polymorphisms of ABCG5 and ABCG8 genes on ezetimibe lipid-lowering response. Int. J. Morphol., 30(2):688-695, 2012.

SUMMARY: In this study we evaluated the possible association between five single nucleotide polymorphisms in ABCG5 (rs6720173) and ABCG8 (rs11887534, rs4148211, rs4148217 and rs6544718) genes and ezetimibe response in Chilean hypercholesterolemic subjects. A total of 60 non-related hypercholesterolemic subjects, aged 18 to 65 years old were included in this study. These subjects were treated with ezetimibe (10mg/day) during one month. The ABCG5 and ABCG8 genotypes were assessed by PCR-RFLP. The genotype distribution of the ABCG5/ABCG8 polymorphisms was in Hardy-Weinberg equilibrium. Our results showed that the investigated polymorphisms were not associated with the response to ezetimibe. Nevertheless, the $\mathrm{T}$ allele of rs6544718 polymorphism was related to higher baseline levels of LDL-cholesterol ( $\mathrm{p}<0.001)$. In addition, the $\mathrm{G}$ allele for the rs 4148211 polymorphism was associated with greater baseline concentrations of triglycerides $(\mathrm{P}=0.019)$. This allele was also associated with lower concentrations of HDL-cholesterol ( $\mathrm{P}=0.027)$, after ezetimibe treatment. Our results suggest that the studied polymorphisms do not affect the therapeutic response to ezetimibe in the evaluated subjects.

KEY WORDS: Ezetimibe; Cholesterol; ABCG5/G8; Polymorphisms.

\section{INTRODUCTION}

Ezetimibe is a selective cholesterol absorption inhibitor that prevents biliary and dietary cholesterol transport in small intestine (Kosoglou et al., 2005) blocking Niemann-Pick C1 like-1 (NPC1L1) protein (Garcia-Calvo et al., 2005). Ezetimibe reduce LDL-C safely in a range of $20-25 \%$ and can be used as monotherapy or in combination with statins (Sudhop et al., 2002; Kosoglou et al.; GarciaCalvo et al.). Despite of this effectiveness, it has been reported that exists a significantly inter-individual variation in LDL-C response to ezetimibe treatment (Sudhop et al.). Single nucleotide polymorphism in NPC1L1 gene could be responsible for this variability (Wang et al., 2004). NPC1L1 gene variations have been associated with LDLC response to ezetimibe-statin therapy (Simon et al., 2005). For instance, carrier's of common haplotype of NPC1L1, haplotype 2, show a LDL-C reduction related to ezetimibe into an expected range of $20 \%$ to $25 \%$; however, subjects without haplotype 2, show a LDL-C reduction of 35\% (Hegele et al., 2005). On the other hand, ezetimibe is effective in sitosterolemia, a disease characterized by intestinal plant sterol hyperabsorption state caused by mutations in ABCG5 and ABCG8 cholesterol transporters (Klett \& Patel, 2004) Interestingly, gene polymorphism in ABCG5 and G8 has been associated to variations on plasma lipids levels (Berge et al., 2002; Weggemans et al., 2002; Hubácek et al., 2004; Acalovschi et al., 2006; Wang et al., 2007) and in hypercholesterolemic subjects; the D19H variant in ABCG8 is associated with greater LDL-C lowering response to atorvastatin therapy (Kajinami et al., 2004a, 2004b).

In view of these antecedents, we hypothesized that genetic variations that affect these proteins can be influencing the inter-individual variation in response to ezetimibe. Thus, the aim of the present study was to evaluate the possible association between five common gene polymorphisms in the ABCG5/ABCG8 genes and the ezetimibe response in Chilean hypercholesterolemic subjects.

\footnotetext{
* Centro de Biología Molecular \& Farmacogenética, Departamento de Ciencias Básicas, Facultad de Medicina; Núcleo Científico-Tecnológico en Biorecursos (BIOREN), Universidad de La Frontera, Temuco, Chile.

** Departamento de Medicina Interna, Facultad de Medicina, Universidad de La Frontera, Temuco, Chile.

This study was supported by grants from Dirección de Investigación y Desarrollo, Universidad de La Frontera (DIUFRO DI09-1007).
} 


\section{MATERIAL AND METHOD}

Subjects and Study Protocol. We studied 60 individuals (17 male and 43 female) non related, with clinical and laboratory diagnosis of hypercholesterolemia (LDL cholesterol $>160 \mathrm{mg} / \mathrm{dL}$ [ $4.14 \mathrm{mmol} / \mathrm{L}]$ ), according to NCEP criteria (Grundy et al., 2004) from Temuco city (Chile). These subjects were treated with $10 \mathrm{mg} /$ day of ezetimibe (Zient*, Schering-Plough, Puerto Rico) for one month, after a four-week washout period including ATP step 2 diet (Grundy et al.). None of the subjects had gallstone disease, cholestasis, diabetes mellitus, hepatic disease, renal disease, endocrinological disorders or malignant disease. Patients with clinical diagnosis of familial hypercholesterolemia $(\mathrm{FH})$ were also excluded. Information of age, height, weight, hypertension, obesity, tobacco smoking, alcohol consumption, physical activity, menopause status, hormone replacement therapy, familial history of coronary artery disease and medication was recorded. None of the study subjects had supplemented with phytosterols. Women with hormone replacement therapy were not included in this protocol. All the participants voluntarily signed an informed consent. The study protocol was approved by the Ethics Committee of our University.

Biochemical Measurements. Blood samples were obtained by venipuncture following a 10 to 12 -h overnight fast. Serum total cholesterol, high-density lipoprotein cholesterol (HDLC) and triglycerides levels were determined by enzymaticcolorimetric methods (Burstein et al., 1970; Fossati \& Principe, 1982; Fossati \& Medicci, 1987) and the low-density lipoprotein cholesterol was calculated by Friedewald formula, when the triglyceride levels did not exceed $400 \mathrm{mg} /$ dL (Friedewald et al., 1972). The accuracy of the biochemical determinations was controlled using normal and pathological commercial serums (Human, Germany).

Molecular Analysis. Genomic DNA was extracted from blood leukocytes by a salting out procedure optimized by Salazar et al. (1998) We analysed the ABCG5 rs6720173 gene polymorphism using polymerase chain reaction (PCR) followed by enzymatic restriction according to conditions described by Hubácek et al. For the ABCG8 gene, we studied the rs11887534, rs4148211, rs4148217 and rs6544718 single nucleotide polymorphisms. The correct assessment of genotypes was evaluated using a homozygous sample for restriction site as a positive control. In addition, all gels were reread blindly by two persons without any change, and $20 \%$ of the analyses were repeated randomly.

Statistical Analysis. The analysis of the collected data was done using the SigmaPlot program for Windows, version
11.0 (Systat Software Inc., USA). Normal distribution and homogeneity of variance were confirmed before further analysis. Association between the different analyzed variables was verified using Student $t$ test or one-way ANOVA. Multiple comparisons were performed by Bonferroni test. For comparison of proportions and evaluation of HardyWeinberg equilibrium we used Chi-square test (c2). Statistical significance was at $\mathrm{P}<0.05$.

\section{RESULTS}

Characteristics of the Study Group. The clinical and laboratory characteristics of the studied subjects are given in Table I. As showed in Table II, the serum total cholesterol and LDL-C levels were lower after ezetimibe treatment (P $<0.001)$ demonstrating the effectiveness in lipid reduction. On the other hand, serum HDL-C and triglycerides concentrations were not statistically different after treatment $(\mathrm{P}=\mathrm{NS})$. The Figure 1 shows the individual response to ezetimibe $(10 \mathrm{mg} / \mathrm{day} / 1 \mathrm{month})$ in the 60 studied subjects. Considering the serum LDL-C levels as the efficacy variable, it is possible to appreciate the broad variability to ezetimibe response, with LDL-C reductions between -6 and $-52 \%$. Moreover, 8 subjects increased serum levels of LDL$\mathrm{C}$ between +5 and $+39 \%$.

Table I. Clinical and demographic characteristics of individuals studied.

\begin{tabular}{|c|c|}
\hline Parameters & Patients $(\mathrm{n}=60)$ \\
\hline Age (years) & $51 \pm 9$ \\
\hline Gender (Female), \% & 72 \\
\hline Ethni city (Amerindian), \% & 90 \\
\hline Menopause status; $\%$ & 28 \\
\hline Cigarrete smoking, $\%$ & 20 \\
\hline BMI, $\mathbf{k g} / \mathrm{m}^{2}$ & $28.7 \pm 4.4$ \\
\hline SBP, mmHg & $132 \pm 22$ \\
\hline DBP, mmHg & $79 \pm 12$ \\
\hline WHR & $0.918 \pm 0.08$ \\
\hline Glucose, $\mathbf{m g} / \mathbf{d L}$ & $97 \pm 15$ \\
\hline Total cholesterol, mg/dL & $271 \pm 29$ \\
\hline LDL-C, mg/dL & $181 \pm 32$ \\
\hline HDL-C, mg/dL & $44 \pm 14$ \\
\hline Triglycerides, mg/dL & $150 \pm 47$ \\
\hline
\end{tabular}

BMI, body mass index; LDL-C, low density lipoproteincholesterol; HDL-C, high density lipoprotein-cholesterol; DBP, diastolic blood pressure; SBP, systolic blood pressure; WHR, waist-hip ratio. 
Table II. Serum lipid profile of Chilean hypercolesterolemic subjects after and before ezetimibe treatment.

\begin{tabular}{lccr}
\hline & Basal & Ezetimibe & $* \mathbf{P}$ \\
\hline Total cholesterol, mg/dL & $271 \pm 29$ & $222 \pm 34$ & $<0.001$ \\
LDL - C, $\mathbf{~ m g / d L}$ & $181 \pm 32$ & $138 \pm 24$ & $<0.001$ \\
HDL - C, mg/dL & $44 \pm 14$ & $42 \pm 13$ & 0.621 \\
Triglycerides, mg/dL & $150 \pm 47$ & $150 \pm 66$ & 0.581 \\
\hline
\end{tabular}

LDL-C, low density lipoprotein-cholesterol; HDL-C, high density lipoprotein-cholesterol. Values are expressed as mean $\pm \mathrm{SD}$. $* P$ values from paired $t$ test.

Table III. Genotype distribution and relative allele frequencies of ABCG5 and ABCG8 polymorphisms in Chilean subjects with hypercholesterolemia.

\begin{tabular}{|c|c|c|c|c|c|c|}
\hline \multirow{2}{*}{$\begin{array}{l}\text { Gene } \\
\text { ABCG5 }\end{array}$} & \multirow{3}{*}{$\begin{array}{c}\text { Polymorphism } \\
\text { rs6720173 C>G } \\
\text { (Gln604Glu) }\end{array}$} & \multicolumn{3}{|c|}{ Genotypes (\%) } & \multicolumn{2}{|c|}{ Alleles } \\
\hline & & $\mathrm{CC}$ & $\mathrm{CG}$ & GG & $\mathrm{C}$ & $\mathrm{G}$ \\
\hline & & $13(8)$ & $57(34)$ & $30(18)$ & 0.420 & 0.580 \\
\hline \multirow[t]{8}{*}{ ABCG8 } & rs4148211 A>G & AA & AG & GG & A & G \\
\hline & (Tyr54Cys) & $27(16)$ & $50(30)$ & $23(14)$ & 0.520 & 0.480 \\
\hline & rs4148217 C>A & $\mathrm{CC}$ & CA & AA & $\mathrm{C}$ & A \\
\hline & (Thr400Lys) & $45(27)$ & $50(30)$ & $5(3)$ & 0.700 & 0.300 \\
\hline & rs6544718 C>T & $\mathrm{CC}$ & CT & TT & $\mathrm{C}$ & $\mathrm{T}$ \\
\hline & (Ala632Val) & $65(39)$ & $32(19)$ & $3(2)$ & 0.800 & 0.200 \\
\hline & rs $11887534 \mathrm{G}>\mathrm{C}$ & GG & GC & $\mathrm{CC}$ & G & $\mathrm{C}$ \\
\hline & (Asp19His) & $82(49)$ & $18(11)$ & $0(0)$ & 0.910 & 0.090 \\
\hline
\end{tabular}

Number of individuals in parenthesis. Hardy-Weinberg Equilibrium: rs6720173 $\chi 2=1.65, P=\mathrm{NS} ; \mathbf{r s 4 1 4 8 2 1 1}$ $\chi 2=0.000742, P=\mathrm{NS} ; \mathrm{rs} 4148217 \chi 2=2.18, P=\mathrm{NS} ; \mathrm{rs} 6544718 \chi 2=0.03, P=\mathrm{NS} ; \mathrm{rs} 11887534 \chi 2=0.61, P=$ NS

Table IV. Response to ezetimibe treatment (10 mg/day/1 month) according to genotypes for rs6720173 ABCG5 gene polymorphism in Chilean subjects with hypercholesterolemia.

\begin{tabular}{lccccc}
\hline Parameters & & CC $(\mathbf{n}=\mathbf{8})$ & $\mathbf{C G}(\mathbf{n}=\mathbf{3 4})$ & $\mathbf{G G}(\mathbf{n}=\mathbf{1 8})$ & P* \\
\hline Total cholesterol, mg/dL & Basal & $280 \pm 31$ & $273 \pm 27$ & $266 \pm 32$ & 0.325 \\
& Ezetimibe & $225 \pm 39$ & $218 \pm 28$ & $231 \pm 42$ & 0.417 \\
& \% Change & $-20 \pm 9$ & $-19 \pm 11$ & $-13 \pm 15$ & 0.146 \\
\hline LDL-C, mg/dL & Basal & $193 \pm 31$ & $175 \pm 23$ & $186 \pm 39$ & 0.400 \\
& Ezetimibe & $151 \pm 47$ & $133 \pm 21$ & $149 \pm 33$ & 0.251 \\
& \% Change & $-29 \pm 10$ & $-23 \pm 19$ & $-16 \pm 24$ & 0.409 \\
\hline HDL-C, mg/dL & Basal & $43 \pm 10$ & $45 \pm 16$ & $42 \pm 13$ & 0.781 \\
& Ezetimibe & $43 \pm 12$ & $42 \pm 14$ & $43 \pm 10$ & 0.723 \\
& \% Change & $-1 \pm 9$ & $-4 \pm 19$ & $7 \pm 29$ & 0.547 \\
\hline Triglycerides, mg/dL & Basal & $159 \pm 40$ & $146 \pm 47$ & $204 \pm 60$ & 0.210 \\
& Ezetimibe & $113 \pm 37$ & $127 \pm 50$ & $204 \pm 38$ & 0.062 \\
& \% Change & $-14 \pm 22$ & $-7 \pm 35$ & $-2 \pm 28$ & 0.424 \\
\hline
\end{tabular}

LDL-C, low density lipoprotein-cholesterol; HDL-C, high density lipoprotein-cholesterol. ${ }^{*} P$ values from ANOVA.

690
Genetic Variants and Ezetimibe Lipid-lowering Therapy. The genotype distribution and the relative allele frequencies for the rs6720173 (ABCG5) and the rs11887534, rs4148211, rs4148217 and rs6544718 (ABCG8) gene polymorphisms are shown in the Table 3. All frequencies of the genotypes were in Hardy Weinberg equilibrium (Table III).

We did not find any association between ABCG5 rs6720173 gene polymorphism and serum lipids levels before and after ezetimibe treatment $(\mathrm{P}=\mathrm{NS}$, Table IV). For the ABCG8 gene, the group of patients with GG genotype for the rs 4148211 polymorphism, after ezetimibe treatment, showed lower levels of HDL-C $(\mathrm{P}=0.027)$ when compared to AA and AG genotype (Table V). Similarly, the subjects with GG genotype showed higher basal levels of triglycerides $(\mathrm{P}=0.019)$ compared to AA and $A G$ genotype. We did not observed significant differences for the serum total cholesterol and LDL-C levels.

The analysis of rs6544718 polymorphism of ABCG8 gene show that the carriers of TT genotype showed higher basal serum levels of LDL-C $(281 \pm 1$ $\mathrm{mg} / \mathrm{dL}, \mathrm{P}<0.001$, Table VI) than CC $(176 \pm 23 \mathrm{mg} / \mathrm{dL})$ and CT genotypes $(185 \pm 30$ $\mathrm{mg} / \mathrm{dL}$ ). On the other hand, the statistical analysis between the different genotypes of rs11887534 and rs4148217 polymorphisms of ABCG8 gene did not show significant differences for the serum levels of total cholesterol, LDL-C, HDL-C and triglycerides before or after ezetimibe treatment (Tables VII and VIII, respectively). 
Table V. Response to ezetimibe treatment (10 mg/day/1 month) according to genotypes for rs4148211 ABCG8 gene polymorphism in Chilean subjects with hypercholesterolemia.

\begin{tabular}{lccccc}
\hline Parameters & & AA $(\mathbf{n}=\mathbf{1 6})$ & AG $(\mathbf{n}=\mathbf{3 0})$ & GG $(\mathbf{n}=\mathbf{1 4})$ & P* \\
\hline Total cholesterol, mg/dL & Basal & $274 \pm 37$ & $271 \pm 26$ & $271 \pm 29$ & 0.898 \\
& Ezetimibe & $214 \pm 29$ & $228 \pm 36$ & $221 \pm 35$ & 0.483 \\
& \% Change & $-21 \pm 12$ & $-16 \pm 13$ & $-18 \pm 13$ & 0.356 \\
\hline LDL-C, mg/dL & Basal & $177 \pm 42$ & $190 \pm 27$ & $180 \pm 24$ & 0.120 \\
& Ezetimibe & $133 \pm 25$ & $140 \pm 31$ & $142 \pm 37$ & 0.876 \\
& \% Change & $-23 \pm 21$ & $-21 \pm 20$ & $-22 \pm 19$ & 0.794 \\
\hline HDL-C, mg/dL & Basal & $48 \pm 12$ & $43 \pm 13$ & $42 \pm 19$ & 0.059 \\
& Ezetimibe & $45 \pm 12$ & $42 \pm 10$ & $35 \pm 8$ & 0.027 \\
\hline Triglycerides, mg/dL & \% Change & $-5 \pm 13$ & $3 \pm 22$ & $-3 \pm 28$ & 0.380 \\
\hline & Basal & $115 \pm 44$ & $151 \pm 39$ & $175 \pm 32$ & 0.019 \\
& Ezetimibe & $118 \pm 44$ & $137 \pm 34$ & $136 \pm 56$ & 0.505 \\
& \% Change & $-4 \pm 22$ & $-4 \pm 34$ & $-14 \pm 36$ & 0.874 \\
\hline
\end{tabular}

LDL-C, low density lipoprotein-cholesterol; HDL-C, high density lipoprotein-cholesterol. * $P$-values from ANOVA. Multiple comparisons by Bonferroni test.

Table VI. Response to ezetimibe treatment (10 mg/day/1 month) according to genotypes for rs6544718 ABCG8 gene polymorphism in Chilean subjects with hypercholesterolemia.

\begin{tabular}{lccccc}
\hline Parameters & & CC $(\mathbf{n}=\mathbf{3 9})$ & $\mathbf{C T}(\mathbf{n}=\mathbf{1 9})$ & TT $(\mathbf{n}=\mathbf{2})$ & P* \\
\hline Total cholesterol, mg/dL & Basal & $269 \pm 26$ & $273 \pm 31$ & $313 \pm 62$ & 0.124 \\
& Ezetimibe & $222 \pm 34$ & $220 \pm 35$ & $256 \pm 8$ & 0.206 \\
& \% Change & $-17 \pm 13$ & $-19 \pm 13$ & $-16 \pm 14$ & 0.818 \\
\hline LDL-C, mg/dL & Basal & $180 \pm 22$ & $186 \pm 30$ & $281 \pm 1$ & $<0.001$ \\
& Ezetimibe & $133 \pm 17$ & $142 \pm 43$ & $163 \pm 31$ & 0.403 \\
HDL-C, mg/dL & \% Change & $-19 \pm 20$ & $-26 \pm 21$ & $-28 \pm 9$ & 0.293 \\
\hline Triglycerides, mg/dL & Basal & $43 \pm 12$ & $45 \pm 18$ & $47 \pm 13$ & 0.866 \\
& Ezetimibe & $42 \pm 10$ & $43 \pm 17$ & $48 \pm 17$ & 0.565 \\
& \% Change & $2 \pm 25$ & $-4 \pm 16$ & $2 \pm 7$ & 0.822 \\
& Basal & $142 \pm 40$ & $146 \pm 47$ & $93 \pm 2$ & 0.272 \\
& Ezetimibe & $127 \pm 41$ & $132 \pm 42$ & $93 \pm 2$ & 0.476 \\
\hline
\end{tabular}

LDL-C, low density lipoprotein-cholesterol; HDL-C, high density lipoprotein-cholesterol. ${ }^{*} P$-values from ANOVA. Multiple comparisons by Bonferroni test.

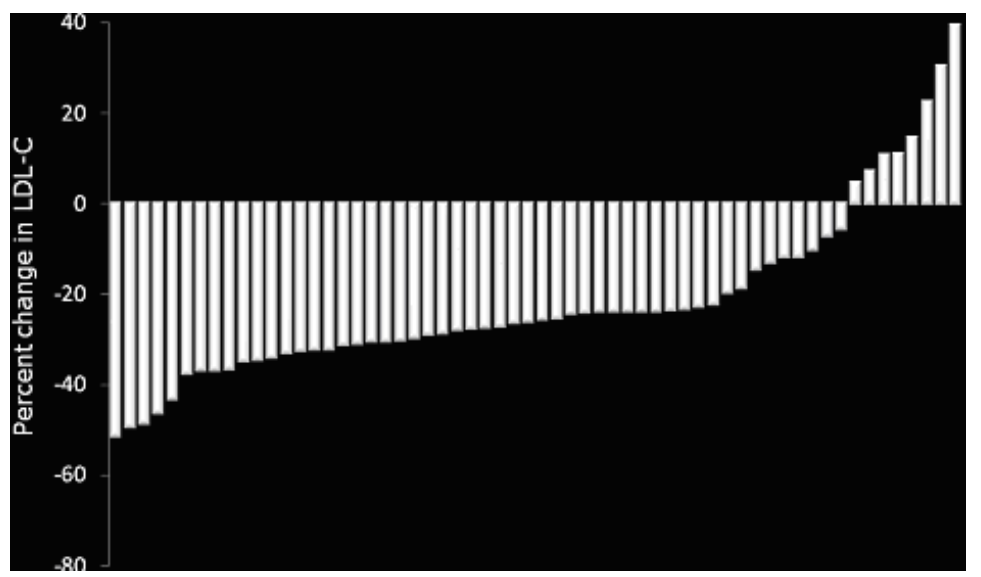

Fig. 1. Individual therapeutic response to ezetimibe $10 \mathrm{mg} /$ day/4 weeks, considering the serum LDL-C values as efficacy variable. Each bar represents the percent change in LDL-cholesterol from baseline for one study subject; these data are arranged in rank order to show the range of responses. 
Table VII. Response to ezetimibe treatment (10 mg/day/1 month) according to genotypes for rs11887534 ABCG8 gene polymorphism in Chilean subjects with hypercholesterolemia.

\begin{tabular}{lcccc}
\hline Parameters & & GG $(\mathbf{n}=\mathbf{4 9})$ & GC $(\mathbf{n}=\mathbf{1 1})$ & P* \\
\hline Total cholesterol, mg/dL & Basal & $271 \pm 30$ & $277 \pm 27$ & 0.385 \\
& Ezetimibe & $223 \pm 35$ & $219 \pm 28$ & 0.969 \\
& \% Change & $-17 \pm 13$ & $-21 \pm 12$ & 0.738 \\
\hline LDL-C, mg/dL & Basal & $189 \pm 31$ & $162 \pm 20$ & 0.047 \\
& Ezetimibe & $139 \pm 29$ & $130 \pm 21$ & 0.957 \\
& \% Change & $-22 \pm 20$ & $-20 \pm 22$ & 0.594 \\
\hline HDL-C, mg/dL & Basal & $44 \pm 14$ & $45 \pm 16$ & 0.774 \\
& Ezetimibe & $43 \pm 13$ & $41 \pm 13$ & 0.321 \\
& \% Change & $1 \pm 23$ & $-7 \pm 16$ & 0.330 \\
\hline Triglycerides, mg/dL & Basal & $144 \pm 37$ & $157 \pm 81$ & 0.664 \\
& Ezetimibe & $129 \pm 39$ & $122 \pm 56$ & 0.751 \\
& \% Change & $-7 \pm 32$ & $-1 \pm 25$ & 0.599 \\
\hline
\end{tabular}

LDL-C, low density lipoprotein-cholesterol; HDL-C, high density lipoprotein-cholesterol. *-values from paired t test.

Table VIII. Response to ezetimibe treatment (10 mg/day/1 month) according to genotypes for rs4148217 ABCG8 gene polymorphism in Chilean subjects with hypercholesterolemia.

\begin{tabular}{lccccc}
\hline Parameters & & $\mathbf{C C}(\mathbf{n}=\mathbf{2 7})$ & $\mathbf{C A}(\mathbf{n}=\mathbf{3 0})$ & $\mathbf{A A}(\mathbf{n}=\mathbf{3})$ & $\mathbf{P}^{*}$ \\
\hline Total cholesterol, mg/dL & Basal & $274 \pm 28$ & $269 \pm 31$ & $275 \pm 33$ & 0.934 \\
& Ezetimibe & $225 \pm 38$ & $222 \pm 30$ & $208 \pm 43$ & 0.697 \\
& \% Change & $-18 \pm 12$ & $-16 \pm 14$ & $-25 \pm 6$ & 0.509 \\
\hline LDL-C, mg/dL & Basal & $190 \pm 31$ & $184 \pm 32$ & $175 \pm 19$ & 0.759 \\
& Ezetimibe & $138 \pm 32$ & $145 \pm 30$ & $113 \pm 10$ & 0.225 \\
& \% Change & $-24 \pm 17$ & $-18 \pm 23$ & $-28 \pm 9$ & 0.570 \\
\hline HDL-C, mg/dL & Basal & $43 \pm 17$ & $45 \pm 13$ & $45 \pm 8$ & 0.521 \\
& Ezetimibe & $42 \pm 15$ & $43 \pm 11$ & $44 \pm 5$ & 0.645 \\
& \% Change & $2 \pm 28$ & $-2 \pm 16$ & $-2 \pm 5$ & 0.900 \\
\hline Triglycerides, mg/dL & Basal & $140 \pm 43$ & $145 \pm 43$ & $143 \pm 4$ & 0.940 \\
& Ezetimibe & $127 \pm 36$ & $128 \pm 47$ & $124 \pm 30$ & 0.989 \\
& \% Change & $-4 \pm 23$ & $-7 \pm 37$ & $-15 \pm 16$ & 0.490 \\
\hline
\end{tabular}

LDL-C, low density lipoprotein-cholesterol; HDL-C, high density lipoprotein-cholesterol. ${ }^{*} P$-values from ANOVA.

\section{DISCUSSION}

The monotherapy with ezetimibe decreased LDL$\mathrm{C}$ levels in $18 \%$ and total cholesterol in $12 \%$ (Torres et al., 2009). In our study, the administration of $10 \mathrm{mg} /$ day for one month of ezetimibe caused a reduction of $21 \%$ in serum levels of LDL-C, confirming the effectiveness of ezetimibe treatment. However, a proportion of subjects (13\%) did not show any response and increased their plasma LDL-C levels. This variability in ezetimibe response has been explained in part, by the presence of variants in NPC1L1 gene (Hegele $e t$ al.). In the present study, we investigated the possible association between polymorphisms in ABCG5 (rs6720173) and ABCG8 (rs11887534, rs4148211, rs4148217 and rs6544718) genes, and the therapeutic response to ezetimibe in 60 Chilean hypercholesterolemic subjects.

Our results showed that rs6720173 polymorphism of ABCG5 gene are not associated with the response to ezetimibe treatment in the population studied. Similarly, in hypercholesterolemic patients from USA, no association was found between this polymorphism and lipids levels before 
and after atorvastatin treatment (Kajinami et al., 2004a). Likewise, Hubáceck et al. did not associate this genetic variant and lipids levels in Czech population. In Mexican hypercholesterolemic subjects, this polymorphism was not significantly associated with reduction in plasma lipids (Torres et al.). Interestingly, Viturro et al. (2006) found no association among this genetic variant and lipids levels. Nevertheless, when the subjects were separated by lipid intake, the variant rs6720173 C/G of ABCG5 gene was associated with plasma total cholesterol, LDL-C and apolipoprotein B levels. Similarly, Acalovschi et al. found a positive association between rs6720173 C/G and higher lipid levels in siblings with gallstones. The presence of $\mathrm{C}$ allele was associated with higher levels of total cholesterol and triglycerides. Recently, in Japanese subjects, it was established that carriers of CC genotype have an increased risk in developing gallstones independently of age, sex and body mass index (Kuo et al., 2008). Moreover, this polymorphism was associated to insulin sensibility in hypercholesterolemic from Finland (Gylling et al., 2004). In addition, Herron et al. described that carriers of $G$ allele have a minor response to diet cholesterol (Herron et al., 2006). An interesting association was established between this polymorphism and weight reduction in Canadian women, the carriers of GG variant experimented a major reduction in cholesterol absorption compared to CC and GC (Santosa et al., 2007).

In relation with $\mathrm{rs} 4148211 \mathrm{~A} / \mathrm{G}$ polymorphism of ABCG8 gene, we observed that after ezetimibe treatment, the carriers of GG genotype showed lower levels of HDL-C $(35 \pm 8 \mathrm{mg} / \mathrm{dL})$ compared to carriers of AA $(45 \pm 12 \mathrm{mg} / \mathrm{dL})$ and $A G(42 \pm 10 \mathrm{mg} / \mathrm{dL})$ genotypes $(\mathrm{P}=0.027)$. This result is in concordance with Junyent et al. (2009), who described those carriers of $\mathrm{G}$ allele of rs4148211 polymorphism showed lower levels of HDL-C and higher levels of triglycerides. Similarly, in a group of siblings with gallstones studied by Acalovschi et al., higher levels of triglycerides were associated with the polymorphism rs4148211. In our study, this association was observed in carriers of AA genotype. The association with the values of HDL-C is concordant with the reported by Hubáceck et al., who established that rs4148211 A/G gene polymorphism can be influencing the lipid levels in a gender and gene-nutrition form. They concluded that women carriers of GG genotype showed stables levels of cholesterol and non response to dietary changes; however, carriers of AA genotype had a mayor reduction in plasma cholesterol between 1988 and 1996. On the other hand, our results for this polymorphism differ with Miwa et al. (2005) who did not find any association with this genetic variant and lipid levels in patients from Japan. Similarly, Wang et al. (2007) did not find significant differences in plasma and biliary lipid levels. Moreover, this polymorphism was evaluated in atorvastatin treatment without finding any significant association (Kakinami et al., 2004a).

The analysis of rs4148217 C/A polymorphism of ABCG8 gene did not show significant differences in plasma lipids levels between genotypes before and after ezetimibe treatment. In a similar form, this variant was not associated with atorvastatin response (Kajinami et al., 2004a; Kajinami et al., 2004b) However, Berge et al. (2002) associated the rs4148217 polymorphism with lower concentrations of sterol. In another study, Zhao et al. (2008) established that carriers of A allele with higher basal levels of plant sterols reduce LDL-C in a mayor proportion that subjects with the same genotype but with lower basal levels of plant sterols. On the other hand, Miwa et al. failed to associate rs 4148217 polymorphism with changes in plasma lipids levels. On the opposite, Hubáceck et al. showed an association between this polymorphism and changes in lipids levels in males. Interestingly, Wang et al. (2007) showed a similar relation among gender and genetic variant in male production of gallstones. Similarly, Junyent et al. described that only smokers and the homozygous CC genotype, showed lower values of HDL-C compared to carriers of A allele (39.9 \pm 11.0 vs. $46.2 \pm 15.0 \mathrm{mg} / \mathrm{dL} ; \mathrm{P}<0.001)$.

Another genetic variant investigated in our study was rs6544718 C/T of ABCG8 gene. Before ezetimibe treatment carriers of TT genotype showed higher levels of LDL-C (281 $\pm 0.7 \mathrm{mg} / \mathrm{dl}, \mathrm{P}<0.001)$ compared to $\mathrm{CC}(176 \pm 23 \mathrm{mg} / \mathrm{dl})$ and CT genotypes $(185 \pm 30 \mathrm{mg} / \mathrm{dl})$. Contrarily, Kajinami et al. (2004a) did not find any association between this genetic variant and lipids levels before and after atorvastatin treatment. They did not observed relation with this polymorphism and A-204C of CYP7A1 gene variant. Similarly, Hubáceck et al. did not demonstrate any association with serum lipid values.

Finally, the statistical analysis of rs11887534 G/C polymorphism of ABCG8 gene did not show differences in lipids values before and after ezetimibe treatment. These results are concordant with Hubáceck et al. in Czech population. On the other hand, in subjects treated with atorvastatin this genetic variant of ABCG8 was the only one associated to a mayor reduction of LDL-C but not with total cholesterol levels. The $\mathrm{G}$ allele carriers showed a mayor reduction than $\mathrm{C}$ carriers (Kajinami et al., 2004a; Kajinami et al. 2004b). In this way, Berge et al. established that the variation in plasma sterols levels is highly heritability and this polymorphism can partly explain this variation. In Puerto Rican population, the $\mathrm{G}$ allele summed to other variants in ABCG5 and G8 genes was significantly associated to lower concentrations of HDL-C in smokers, showing an interesting interaction between gene and smoking habit (Junyent et al., 2009). Moreover, Koeijvoets 
et al. (2009) associated this polymorphism with a mayor risk of developing coronary artery disease (RR $1.42 ; 95 \% \mathrm{CI}$ 1.04-1.95; $\mathrm{p}=0.03$ ). A recent review (Calandra et al., 2011) described the implications for classification and disease risk of genetic variants of $\mathrm{ABCG} / \mathrm{G} 8$ genes.

In summary, our data suggests that the investigated ABCG5 and ABCG8 gene polymorphisms are not associated to ezetimibe lipid-lowering response in Chilean subjects. However, these findings need to be confirmed with a greater number of samples.

ACKNOWLEDGEMENTS. Ezetimibe was donated by Shering-Plough Cía. Ltda. None of the authors have a relationship with a for-profit company or institution. No competing financial interests exist.

CAAMAÑO, J. M.; SAAVEdRA, N.; ZAMbRANO, T.; LANAS, F. \& SAlAZAR, L. A. Efecto de cinco polimorfismos de los genes ABCG5 y ABCG8 sobre la respuesta hipolipemiante a ezetimiba. Int. J. Morphol., 30(2):688-695, 2012.

RESUMEN: En este estudio se evaluó la posible asociación entre cinco polimorfismos de nucleótido único en los genes ABCG5 (rs6720173) y ABCG8 (rs11887534, rs4148211, rs4148217 y rs6544718) y la respuesta a ezetimiba en pacientes hipercolesterolémicos chilenos. Un total de 60 individuos hipercolesterolemicos, no relacionados, con edades entre 18 y 65 años fueron incluidos. Estos sujetos fueron tratados con ezetimiba (10mg/día) durante un mes. Los genotipos de ABCG5 y ABCG8 fueron evaluados por PCR-RFLP. La distribución de genotipos de los polimorfismos de ABCG5/ABCG8 se encontraba en equilibrio de Hardy-Weinberg. Nuestros resultados mostraron que los polimorfismos estudiados no se asociaron con la respuesta a la ezetimiba. Sin embargo, el alelo T del polimorfismo rs6544718 fue relacionado con niveles basales elevados de LDL-colesterol ( $\mathrm{p}<0,001)$. Además, el alelo $\mathrm{G}$ para el polimorfismo rs4148211 se asoció con una mayor concentración basal de triglicéridos $(\mathrm{p}=$ 0,019). Este alelo también se asoció con concentraciones más bajas de HDL-colesterol ( $\mathrm{p}=0,027)$, después del tratamiento con ezetimiba. Nuestros resultados sugieren que los polimorfismos estudiados no afectan a la respuesta terapéutica a la ezetimiba en los sujetos evaluados.

PALABRAS CLAVE: Ezetimiba; Colesterol; ABCG5/G8; Polimorfismos.

\section{REFERENCES}

Acalovschi, M.; Ciocan, A.; Mostean, O.; Tirziu, S.; Chiorean, E.; Keppeler, H.; Schirin-Sokhan, R. \& Lammert, F. Are plasma lipids levels related to ABCG5/ABCG8 polymorphisms? A preliminary study in siblings with gallstones. Eur. J. Intern. Med., 17(7):490-4, 2006

Berge, K. E.; von Bergmann, K.; Lutjohann, D.; Guerra, R.; Grundy, S. M.; Hobbs H. H. \& Cohen J. C. Heretability of plasma noncholesterol sterols and relationship to DNA sequence polymorphism in ABCG5 and ABCG8. J. Lipid Res., 43(3):48694, 2002.

Burstein, M.; Scholnick, H. R. \& Morfin, R. Rapid method for the isolation of lipoproteins from human serum by precipitation with polyanions. J. Lipid Res., 11(6):583-95, 1970.

Calandra, S.; Tarugi, P.; Speedy, H. E.; Dean, A. F.; Bertolini, S. \& Shoulders, C. C. Mechanisms and genetic determinants regulating sterol absorption, circulating LDL levels, and sterol elimination: implications for classification and disease risk. $J$. Lipid Res., 52(11):1885-926, 2011.

Fossati, P. \& Medicci, R. Abstract Book. International symposium on cholesterol control and cardiovascular diseases: prevention and therapy. Milan, Italy. Apud: Cholesterol-fast color. Tarrytown, N.Y., Bayer Corporation, Diagnostic Division, 1987.

Fossati, P. \& Principe, L. Serum triglycerides determined colorimetrically with an enzyme of low-density lipoprotein cholesterol in plasma without use of the preparative ultracentrifuge. Clin. Chem., 28(10):2077-80, 1982.
Friedewald, W. T.; Levy, R. I. \& Fredrickson, D. S. Estimation of the concentration of low - density lipoprotein cholesterol in plasma, without use of the preparative ultracentrifuge. Clin. Chem., 18(6):499-502, 1972.

Garcia-Calvo, M.; Lisnock, J.; Bull, H. G.; Garcia-Calvo, M.; Lisnock, J.; Bull, H. G.; Hawes, B. E.; Burnett, D. A.; Braun, M. P.; Crona, J. H.; Davis, H. R. Jr.; Dean, D. C.; Detmers, P. A.; Graziano, M. P.; Hughes, M.; Macintyre, D. E.; Ogawa, A.; O'neill, K. A.; Iyer, S. P.; Shevell, D. E.; Smith, M. M.; Tang, Y. S.; Makarewicz, A. M.; Ujjainwalla, F.; Altmann, S. W.; Chapman, K. T. \& Thornberry, N. A. The target of ezetimibe is Niemann-Pick C1-like (NCP1L1). Proc. Natl. Acad. Sci. USA, 102(23):8132-37, 2005.

Grundy, S. M.; Cleeman, J. I.; Merz, C. N.; Brewer, H. B. Jr.; Clark, L. T.; Hunninghake, D. B.; Pasternak, R. C.; Smith, S. C. Jr.; Stone, N. J.; National Heart, Lung, and Blood Institute; American College of Cardiology Foundation \& American Heart Association. Implications of recent clinical trials for the National Cholesterol Education Program Adult Treatment Panel III guidelines. Circulation, 110(2):227-39, 2004.

Gylling, H.; Hallikainen, M.; Pihlajamäki, J.; Agren, J.; Laakso, M.; Rajaratnam, R. A.; Rauramaa, R. \& Miettinen, T. A. Polymorphisms in the ABCG5 and ABCG8 genes associate with cholesterol absorption and insulin sensitivity. J. Lipid Res., 45(9):1660-5, 2004.

Hegele, R.; Guy, J.; Ban, M. \& Wang, J. NPC1L1 haplotype is associated with inter-individual variation in plasma low-density lipoprotein response to ezetimibe. Lipids Health Dis., 4:16, 2005.

Herron, K. L.; McGrane, M. M.; Waters, D.; Lofgren, I. E.; Clark, R. 
M.; Ordovas, J. M. \& Fernandez, M. L. The ABCG5 polymorphism contributes to individual responses to dietary cholesterol and carotenoids in eggs. J. Nutr., 136(5):1161-5, 2006.

Hubácek, J. A.; Berge, K. E.; Stefková, J.; Pitha, J.; Skodová, Z.; Lánská, V. \& Poledne, R. Polymorphisms in ABCG5 and ABCG8 transporters and plasma cholesterol levels. Physiol. Res., 53(4):395-401, 2004.

Junyent, M.; Tucker, K. L, Smith, C. E.; Garcia-Rios, A.; Mattei, J.; Lai, C. Q.; Parnell, L. D. \& Ordovas, J. M. The effects of ABCG5/G8 polymorphisms on plasma HDL cholesterol concentrations depend on smoking habit in the Boston Puerto Rican Health Study. J. Lipid Res., 50(3):565-73, 2009.

Kajinami, K.; Brousseau, M. E.; Nartsupha, C.; Ordovas, J. M. \& Schaefer, E. J. ATP binding cassette transporter G5 and G8 genotypes and plasma lipoprotein levels before and after treatment with atorvastatin. J. Lipid Res., 45(4):653-6, 2004a.

Kajinami, K.; Brousseau, M. E.; Ordovas, J. M. \& Schaefer, E. J. Interactions between common genetic polymorphisms in ABCG5/G8 and CYP7A1 on LDL cholesterol-lowering response to atorvastatin. Atherosclerosis, 175(2):287-93, $2004 \mathrm{~b}$.

Klett, E. \& Patel, S. B. Will the real cholesterol transporter please stand up. Science, 303(5661):1149-50, 2004.

Koeijvoets, K. C.; van der Net, J. B.; Dallinga-Thie, G. M.; Steyerberg, E. W.; Mensink, R. P.; Kastelein, J. J.; Sijbrands, E. J. \& Plat, J. ABCG8 gene polymorphisms, plasma cholesterol concentrations, and risk of cardiovascular disease in familial hypercholesterolemia. Atherosclerosis, 204(2):453-8, 2009.

Kosoglou, T.; Statkevich, P.; Johnson-Levonas, A. O.; Paolini, J. F.; Bergman, A. J. \& Alton, K. B. Ezetimibe. A review of its metabolism, pharmacokinetics and drug interactions. Clin. Pharmacokinet., 44(5):457-94, 2005.

Kuo, K. K.; Shin, S. J.; Chen, Z. C.; Yang, Y. H.; Yang, J. F. \& Hsiao, P. J. Significant association of ABCG5 604Q and ABCG8 D19H polymorphisms with gallstone disease. Br. J. Surg., 95(8):1005-11, 2008.

Miwa, K.; Inazu, A.; Kobayashi, J.; Higashikata, T.; Nohara, A.; Kawashiri, M.; Katsuda, S.; Takata, M.; Koizumi, J. \& Mabuchi, H. ATP-binding cassette transporter G8 M429V polymorphism as a novel genetic marker of higher cholesterol absorption in hypercholesterolaemic Japanese subjects. Clin. Sci. (Lond.), 109(2):183-8, 2005.

Salazar, L. A.; Hirata, M. H.; Cavalli, S. A.; Machado, M. O. \& Hirata, R. D. Optimized procedure DNA isolation from fresh and cryopreserved clotted human blood useful in clinical molecular testing. Clin. Chem., 44(8):1748-50, 1998.

Santosa, S.; Demonty, I.; Lichtenstein, A. H.; Ordovas, J. M. \& Jones, P. J. Single nucleotide polymorphisms in ABCG5 and ABCG8 are associated with changes in cholesterol metabolism during weight loss. J. Lipid Res., 48(12):2607-13, 2007.
Simon, J. S.; Karnoub, M. C.; Devlin, D. J.; Arreaza, M. G.; Qiu, P.; Monks, S. A.; Severino, M. E.; Deutsch, P.; Palmisano, J.; Sachs, A. B.; Bayne, M. L.; Plump, A. S. \& Schadt, E. E. Sequence variation in NPC1L1 and association with improved LDLcholesterol lowering in response to ezetimibe treatment. Genomics, 86(6):648-56, 2005.

Sudhop, T.; Lütjohann, D.; Kodal, A.; Igel, M.; Tribble, D. L.; Shah, S.; Perevozskaya, I. \& von Bergmann, K. Inhibition of intestinal cholesterol absorption by ezetimibe in humans. Circulation, 106(15):1943-8, 2002.

Torres, N.; Guevara-Cruz, M.; Granados, J.; Vargas-Alarcón, G.; González-Palacios, B.; Ramos-Barragan, V. E.; Quiroz-Olguín, G.; Flores-Islas, I. M. \& Tovar, A. R. Reduction of serum lipids by soy protein and soluble fiber is not associated with the ABCG5/G8, apolipoprotein E, and apolipoprotein A1 polymorphisms in a group of hyperlipidemic Mexican subjects. Nutr. Res., 29(10):728-35, 2009.

Viturro, E.; de Oya, M.; Lasunción, M. A.; Gorgojo, L.; Moreno, J. M.; Benavente, M.; Cano, B. \& Garces, C. Cholesterol and saturated fat intake determine the effect of polymorphisms at ABCG5/ABCG8 genes on lipid levels in children. Genet. Med., 8(9):594-9, 2006.

Wang, J.; Williams, C. M. \& Hegele, R. A. Compound heterozygosity for two non-synonymous polymorphism in NPC1L1 in a nonresponder to ezetimibe. Clin. Gen., 67(2):175-7, 2004.

Wang, Y.; Jiang, Z. Y.; Fei, J.; Xin, L.; Cai, Q.; Jiang, Z. H.; Zhu, Z. G.; Han, T. Q. \& Zhang, S. D. ATP binding cassette G8 T400K polymorphism may affect the risk of gallstone disease among Chinese males. Clin. Chim. Acta, 384(1-2):80-5, 2007.

Weggemans, R. M.; Zock, P. L.; Tai, E. S.; Ordovas, J. M.; Molhuizen, H. O. \& Katan M. B. ATP binding cassette G5 C1950G polymorphism may affect blood cholesterol concentrations in humans. Clin. Genet., 62(3):226-9, 2002.

Zhao, H. L.; Houweling, A. H.; Vanstone, C. A.; Jew, S.; Trautwein, E. A.; Duchateau, G. S. \& Jones, P. J. Genetic variation in ABC G5/G8 and NPC1L1 impact cholesterol response to plant sterols in hypercholesterolemic men. Lipids, 43(12):1155-64, 2008.

Correspondence to:

Prof. Dr. Luis Antonio Salazar

Departamento de Ciencias Básicas,

Facultad de Medicina - Universidad de La Frontera

Av. Francisco Salazar 01145. Casilla 54-D

Temuco, Chile

Email: Isalazar@ufro.cl

Received: 01-03-2012

Accepted: 08-04-2012 